\title{
Chitinous Cuticle and Systematic Position of Tardigrada
}

J. C. BUSSERS and CHARLES JEUNIAUX

Laboratories of Animal Morphology, Systematics and Ecology, Zoological Institute. University of Liege, Liege, Belgium

Key Word Index-Tardigrada; Arthropoda; cuticle; chitin.

Abstract-The chitinous nature of the cuticle, jaws and stomodaeum of three species of Tardigrada has been definitely proven using a specific micromethod involving a preparation of purified chitinase. These chemical characteristics are in favour of the phylogenetic closeness between Tardigrada and the Arthropoda.

\section{Introduction}

The tardigrades (or 'water-bears') constitute a class 'incertae sedis'. The most recent opinion is that Tardigrada, as well as Onychophora, diverged early from the root of the arthropod phyletic line. ${ }^{1}$ The tardigrades are believed to be devoid of chitin, owing to the apparent degradation of their cuticle and other skeletic structures when they are treated with hot alkali. These structures are considered to be formed from proteins, ${ }^{2,3}$ or from a 'chitinoid' substance different from true chitin. ${ }^{4}$ The supposed non-chitinous nature of the epidermal cuticular products, is used as an argument by some authors to support the phylogenetic proposals separating Tardigrada far from the Arthropoda.

However, using an enzymic method for the specific detection of chitin, ${ }^{5.6}$ we have been able to ascertain the presence of this polymer in three different species of Tardigrada: Milnesium tardigradum Doyere, Macrobiotus sp. and Echiniscus merokensis Richters.

\section{Results}

The tardigrades were treated successively with dilute hydrochloric acid, cold, hot $\left(70^{\circ}\right)$ and boiling $\left(100^{\circ}\right)$ dilute sodium hydroxide and

finally purified chitinase 7.8 at $\mathrm{pH} 5 \cdot 2$. After treatment with dilute hydrochloric acid, the stylets lying on both sides of the buccal tube of Macrobiotus sp. were entirely dissolved confirming that these organs are calcified.

During the treatment with $\mathrm{NaOH}$ at room temperature and at $70^{\circ}$, the animals were found to be lightened, but without any alteration of the cuticular structures. After treatment with $\mathrm{N} \mathrm{NaOH}$ at $100^{\circ}$ during $3 \mathrm{hr}$, the animals were entirely invisible, even by careful examination with the light microscope. However, if a few drops of Congo-red solution were added, the cuticules rapidly became stained and easy to identify (Figs. 1-6). In the case of Milnesium tardigradum, the visceral organs and the muscles are completely destroyed, but the general body shape and form are not modified (Figs. 1-3). The cuticle appears to be constituted of two layers, the inner one being thicker (Fig. 1). This observation is true for all the specimens so far studied. The palps (Fig. 2) and the claws of the 'legs' (Fig. 4), as well as the internal covering of the stomodaeum are also intact after boiling alkali. We have also observed that the exuviae and at least one layer of the shell of the embryonic eggs persisted after this treatment (Fig. 3).

\footnotetext{
${ }^{1}$ Hyman, L. (1959) The Invertebrates, Vol. V, McGraw-Hill, New York.

${ }^{2}$ Marcus, E. (1927) Zool. Jahrb. Allg. Zool. 44, 323.

${ }^{3}$ Marcus, E. (1928) Zool. Jahrb. Allg. Zool. 45, 99.

${ }^{4}$ Cuenot, L. (1949) in Traité de Zoologie (Grassé, P. P., ed.), Vol. VI, p. 39.

${ }^{5}$ Jeuniaux, Ch. (1963) Chitine et Chitinolyse, Masson, Paris.

${ }^{6}$ Jeuniaux, Ch. (1965) Bull. Soc. Chim. Biol. 47, 2267.

7 Jeuniaux, Ch. (1959) Arch, Inter. Physiol. Biochem. 67, 597.

8Jeuniaux, Ch. (1958) Arch. Inter. Physiol. Biochem. 66, 408.
}

(Received 30 October $1972 . \quad$ Accepted 23 November 1972) 
Similar observations have been made in the case of Macrobiotus sp. (Figs. 5 and 6) and Echiniscus merokensis. However, the cuticle is thinner in these species and is not divided into separate layers. The stomodaeum, the stylet apophyses and the pharyngeal placoides of Macrobiotus (Fig. 5) as well as the claws (Fig. 6) remain undamaged. In Echiniscus, the flimsy appendages such as clavae, bristles and cirrae are destroyed, but the cuticle as a whole and the claws are clearly visible.

When the structures remaining after the action of the hot alkali are incubated in a solution of purified chitinase at $\mathrm{pH} 5 \cdot 2$ and $37^{\circ}$ during $2-4 \mathrm{hr}$, they are rapidly broken up and entirely hydrolysed in the case of all three species studied. On the other hand, if samples were incubated in the buffer solution without the addition of chitinase, they remain unchanged.

\section{Discussion}

The class Tardigrada is generally divided into two orders. Two of the species of tardigrades studied in the present paper (Macrobiotus sp. and Milnesium tardigradum) belong to the order Heterotardigrada while the third, Echiniscus merokensis, belongs to the order Eutardigrada. Our sampling is thus sufficiently representative of the whole class of Tardigrada.

Contrary to the opinion of Marcus, 2,3 we have found that the cuticle and the other skeletic structures secreted by the epidermis of the tardigrades are not destroyed or even dispersed during drastic treatment with hot alkali. The rapid hydrolysis of these structures in a solution of concentrated purified chitinase (a preparation entirely free of other hydrolases ${ }^{7}$ ) clearly demonstrates that the cuticle, the claws and the stomodaeum of the 3 species examined contain a high proportion of true chitin. As in the case of arthropods, chitin is obviously the organic matrix of the cuticle of Tardigrada owing to the fact that the morphological structures are faithfully kept after destruction of the proteins by $\mathrm{NaOH}$. The present observations also show that the stomodaeal invagination is lined with a chitinous cuticle in Tardigrada as in Arthropoda.

The presence of a typical chitinous cuticle and claws, and the existence of a true stomodaeal invagination lined with a chitinous cuticle are two important arguments in favour of the hypothesis that Tardigrada are to be considered as being phylogenetically close to the Arthropoda.

\section{Experimental}

The tardigrades were isolated from mosses, identified and grouped into 3 batches containing respectively 135 specimens of $M$. tardigradum, 620 specimens of Macrobiotus sp. and 20 specimens of E. merokensis. Each batch was successively treated with the following reagents: $0.5 \mathrm{ml}$ of $0.5 \mathrm{~N} \mathrm{HCl}$ at room temp.: $0.5 \mathrm{ml}$ of $\mathrm{N} \mathrm{NaOH}$ at room temp., then at $70^{\circ}$ and finally at $100^{\circ} ; 0.2 \mathrm{ml}$ of purified chitinase (E.C. 3.2.1.14) prepared from submerged cultures of Streptomyces antibioticus 7.8 at $\mathrm{pH} 5 \cdot 2$ (citric acid$\mathrm{Na}_{2} \mathrm{HPO}_{4}$ buffer $0.1 \mathrm{M}$ ). After each treatment, the material was washed with $\mathrm{H}_{2} \mathrm{O}$. After treatment with $\mathrm{N} \mathrm{NaOH}$ at $100^{\circ}$, the residual material was stained by addition of a few drops of Congo-red $1 \%(\mathrm{w} / \mathrm{v})$ to the alkaline solution. 

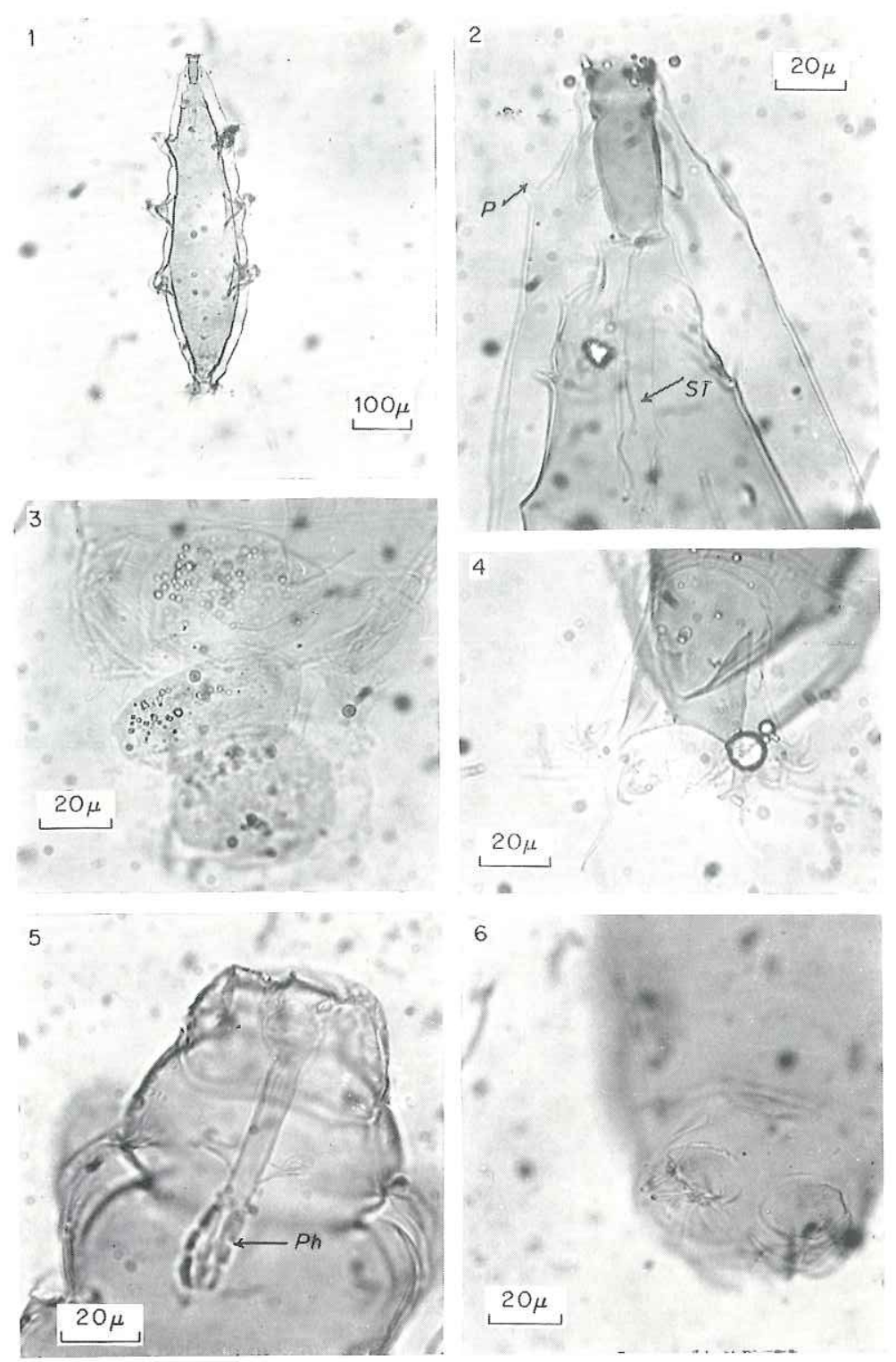

FIGS. 1-6. MICROGRAPHS OF TARDIGRADA AFTER TREATMENT BY N NaOH (100) DURING 3 HR AND AFTER STAINING WITH CONGO-RED. ALL THE VISIBLE STRUCTURES, REMAINING AFTER THIS TREATMENT, ARE RAPIDLY DESTROYED WHEN INCUBATED IN A SOLUTION OF PURIFIED CHITINASE. FIGS, 1-4. MILNESIUM TARDIGRADUM. FIGS. 5 \& 6 . MACROBIOTUS SP.

FIG. 1. THE 2 CUTICULAR LAYERS ARE CLEARLY VISIBLE.

FIG. 2. ANTERIOR PART, SHOWING THE CUTICULAR LINING OF MOUTH, PALPS (P) AND STOMODEUM (ST). FIG. 3, CHITINOUS ENVELOPES OF THREE EMBRYONIC EGGS IN AN EXUVIUM. FIG. 4. CHITINOUS CUTICLE OF THE POSTERIOR LEGS AND OF THEIR CLAWS. FIG. 5. ANTERIOR PART. Ph: PHARYNX.

FIG. 6. POSTERIOR LEGS SHOWING INTACT CLAWS. 